\title{
Martha Cajías: la ilusión de la ruptura
}

Pedro Albornoz

Crítico de arte

\begin{abstract}
In 2003 Martha Cajías worked on a series of drawings entitled Flor de papa. This article focuses on one of these drawings (Flor de Papa 2) and from it, offers an interpretation of the "textile poetics" that gives shape and direction to Cajías' work.
\end{abstract}

\section{Keywords}

creative tension, looms, textile poetics, threads, woven cloth

\section{Resumen}

En el año 2003, Martha Cajías trabajó en una serie de dibujos que tituló Flor de papa. El presente trabajo se concentra en la lectura de uno de estos dibujos (Flor de Papa 2) y, a partir de éste, ofrece una interpretación de la "poética textil" que da forma y sentido a la obra de Cajías.

\section{Palabras claves}

hilos, poética textil, telares, tensión creativa, tela tejida 
El tejido, proyectado desde el uso más cotidiano hasta el ritual más sacro, aglutina y metaforiza todos los momentos de la vida, desde la cuna a la tumba, sin distinción de edad, sexo, estado, creencia u ocupación. Puede combinar la tecnología más avanzada sin perder su fundamento primitivo, constituyéndose, así, como uno de los componentes más importantes de la cultura material de un grupo humano. Martha Cajías sabe esto, entiende que el textil más sencillo se halla imbuido con procesos y energías creativas, anudándose en ideas sencillas y extendiéndose más allá de las posibilidades de la visión, representando desde su unidad mínima las interacciones más complejas posibles, en gradual y constante complejización, fractalidad. Así, ella se vale del textil -cuyo código se genera desde un binarismo esencialcomo herramienta de indagación crítica y medio que le permite evolucionar su reflexión, sintetizar, hibridar y conciliar la complejidad del mundo en una resolución sofisticada, sobria y cargada de sabiduría.

\section{Entre el cielo y el suelo...}

Para comprender mejor a la artista, elegí iniciar mi análisis con una lectura de Flor de papa 2 (fig. 1), un díptico compuesto de dos dibujos a lápiz, carboncillo y tinta, dispuestos verticalmente, uno encima de otro. El dibujo de la parte superior está hecho sobre un papel claro y liso, y muestra un cántaro invertido del cual parecen escapar partículas que pueden interpretarse ya sea como semillas o gotas (¿hilos?) de lluvia; en el trasfondo del cántaro, se perciben manchas nubosas. Por su parte, el dibujo de la parte inferior, elaborado sobre un papel artesanal rescatado de envoltorios y respetando sus arrugas, es oscuro y rugoso; muestra un bulbo orgánico, cubierto con ojos, del cual brotan raíces, por abajo, y pequeñas ramas con hojas que germinan hacia arriba. El título de la obra, así como la literalidad de los ojos, nos lleva a concluir que este bulbo se trata de una papa; por su parte, la disposición en la obra, el tono oscuro y la aspereza del papel -en franco contraste con el dibujo del cántaro- permite inferir que, por oposición, la papa se halla bajo tierra.

En el caso del dibujo del cántaro, hallamos que la artista ha construido una relación poética entre cielo y cántaro, partiendo de la similitud de forma y función: ambos poseen una forma cóncava y son capaces de contener $-\mathrm{y}$ también liberar- agua. Existe, entonces, una comparación implícita de dos objetos/referentes aparentemente disímiles: cielo y cántaro. Además, a partir de la conjunción de ambos elementos, los atributos implícitos y explícitos del referente cántaro sirven para resaltar la descripción del referente cielo, lo que 
nos lleva al entendimiento de que estamos frente a una metáfora. Por su parte, el dibujo de la parte inferior también expresa una hilación poética entre el referente tierra y el referente sustitutivo papa; sin embargo, aquí la relación está fundada en una sustitución de valores de contigüidad espacial más que por similitud de atributos. ${ }^{1}$

Desde este primer nivel de lectura, entonces, el díptico propone que cántaro es a papa lo que cielo es a tierra, una propuesta analógica visual de tal sencillez y elegancia que el placer producido por la experiencia estética derivada de este punto de vista inicial podría abrumar cualquier otra interpretación posible. Sin embargo, la interpretación acaba de empezar.

Este nivel de lectura constituye apenas el primer nudo a partir del cual se ramificarán niveles interpretativos consiguientes que permitirán elaborar una clave de lectura que servirá para dilucidar otras dimensiones de sentido presentes en esta obra y en el resto de la serie de Flor de papa (figs. 2, 3 y 4), pero también en el conjunto total de la producción de Martha.

No podemos descartar como azar la gran similitud entre el contorno del cántaro y el de la papa, cualidad catalizada tanto por los valores tonales en ambos objetos, así como por la soltura del trazo fino de la artista, que otorga por ello una voluptuosidad fluida y orgánica a las dos formas, semejanza que nuevamente nos remite a la metáfora.

${ }^{1}$ Podríamos también activar una relación de semejanza entre papa y tierra al considerar que ambos referentes se parecen por cualidades de forma, color y receptividad en relación al agua y la capacidad germinativa. Sin embargo, esta relación se expresa sólo implícitamente. En contraste, el valor espacial de contigüidad se explicita por la disposición del dibujo, lo que potencia nuestra estrategia de lectura. De todas formas, asumiendo el nivel implícito o explícito, el resultado es el mismo, pues se entiende de ambas formas que tierra = papa. 


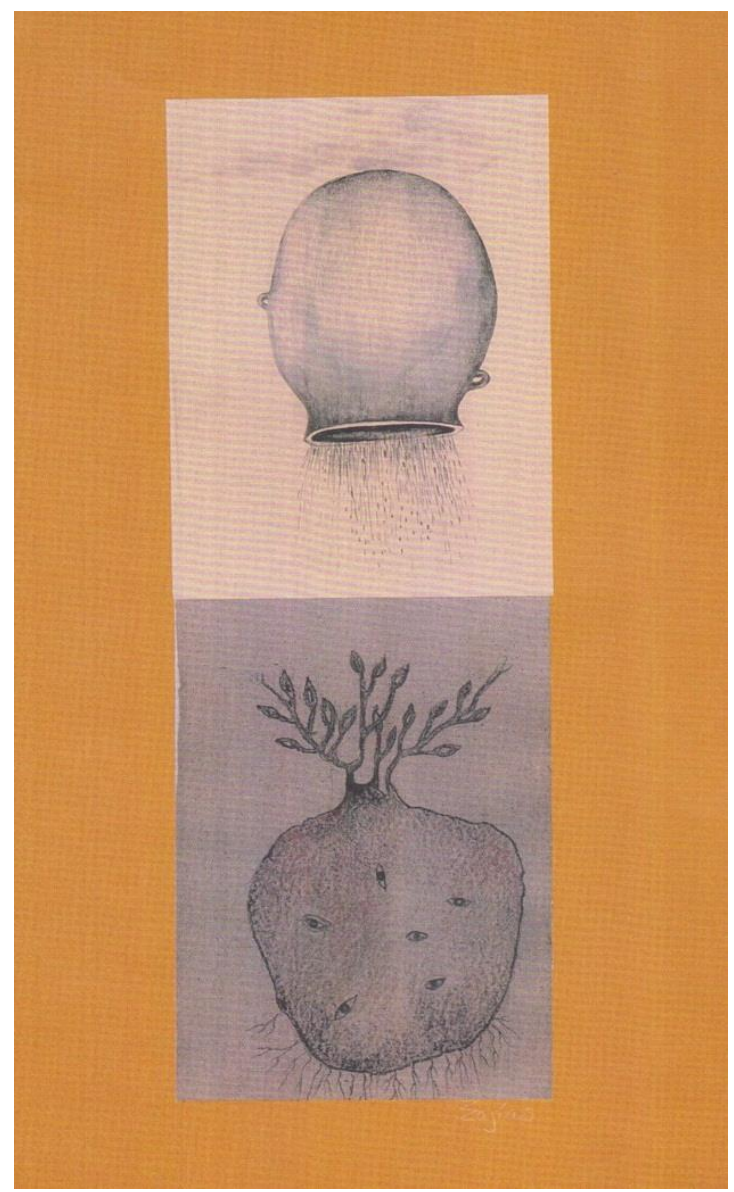

Figura 1. Flor de papa 2 (2003)

Dibujo y técnicas mixtas 


\section{Ecuación poética}

Con estas consideraciones, hallamos que la propuesta de Flor de Papa 2 se complejiza: en el primer nivel interpretativo, si bien vimos que cántaro es a papa lo que cielo es a tierra; empero, al agregar los valores de similitud establecemos nuestro segundo nudo en la siguiente ecuación de correspondencia:

$$
\text { Si cielo = cántaro y papa }=\text { tierra }
$$

Entonces cielo $=$ tierra

En este punto de nuestra interpretación, la experiencia provocada inicialmente por esta composición se intensifica por la exquisitez y elegancia sucinta con la que Martha Cajías elabora y resuelve la propuesta de la obra: una sencillez de forma y economía elemental que responde a una belleza sin lugar a dudas poética, innegablemente matemática, expresada en el método, resultado y experiencia de su obra.

La hermandad formal de ambos dibujos queda también potenciada por la composición simétrica reflectiva, una cualidad que se cimienta con la cercanía de contigüidad: una vez más, entonces, aparece la metonimia como contrapeso dialógico de la metáfora. Entonces, considerando nuevamente el contrapeso creado por los valores de similitud y contigüidad presentes en este segundo nivel, hallamos que la propuesta del díptico se complejiza aún más.

La persistencia de nuestra lectura incide en un cambio de nuestra postura inicial, acercándonos a una experiencia de gozo ante la obra, misma que se consolida al incluir dentro del discurso de nuestra reflexión las tensiones creadas por la artista a partir del uso de las líneas. Por un lado, vemos una línea horizontal continua producida por la unión que hizo la artista de dos papeles de distinta textura y tonalidad. Imbuidos con los hallazgos de la progresión de nuestra interpretación, hallamos que esta línea sirve para dividir no tanto un dibujo del otro, sino, fundamentalmente, los objetos/referentes/espacios metafóricos representados en cada uno. Además, encontramos también una línea sutil vertical, que el espectador debe completar desde lo intuitivo, generada a partir del movimiento de arriba hacia abajo del contenido que cae del cántaro y los brotes de la papa, remitiendo a las correspondencias ocultas entre cielo y tierra, la complementación vital que fluye entre fuerzas contrarias y ocultas. 
Desde este tercer nudo podemos consumar la lectura de esta obra: el díptico nos habla acerca del proceso de creación, de ser y de la unificación generada por la tensión creativa, dinámica, resultante de la unión de opuestos. La elucidación de este juego entre lo invisible y visible, entre lo vertical y lo horizontal, entre el movimiento y la quietud, nos revela el módulo estructural unificador cardinal que recurre, transformado progresivamente, como lógica, motivo y proceso en todas las obras que componen la serie Flor de papa, pero también como un elemento inmanente en toda la obra de Cajías: lo textil.

\section{Parca}

A la vez producto y proceso, el tejido parte de un principio elemental: el entrelazamiento de dos elementos en tensión opuestos a la urdimbre: por una parte, el soporte vertical y estático, y por otra, la trama -el o los sistemas de hilados dinámicos horizontales que pasan por encima o por debajo de la urdimbre, dependiendo del sistema de entrelazamiento. Esta dinámica constituye el cimiento conceptual que se manifiesta en toda la obra de Martha Cajías, percibiéndose, a veces, con la visión (hilos, motivos telares, procesos y productos textiles) y en otras, con la intuición (líneas/hilos sugeridos, lógicas textiles de secuenciamiento, simetría, desplazamiento, repetición, juegos entre símbolos de oposición complementaria).

Esta clave ofrece al espectador la posibilidad de entender obra por obra la producción de la artista, desde sus singularidades, así como también el corpus completo de su propuesta artística: comenzando por la serie flor de papa hasta sus batiks, óleos y otras incursiones. Lo textil está expresado visiblemente como agente de articulación en obras tales como Amuleto: Atajador de granizos, La Seca y la Húmeda, Lunares, -pero también de manera subjetiva, sugerida por el trazo fino, delicado y ondulante de pintura, en sus batiks, especialmente en dibujos como Los Fecundadores, que también explota la composición y disposición de elementos para explicitar tensión y atracción de fuerzas cósmicas, biológicas, entre lo masculino y lo femenino, la gestación y la descomposición.

También sugiere lo textil, recuperando estrategias de codificación textil, Vírgenes y Virginias (figs. 5-9), donde observamos secuencias (los estantes llenos de productos) y la composición simétrica (el cuadro se divide en dos); asimismo, encontramos un juego de simetría de escala entre la imagen de una virgen mestiza con su niño en brazos, a la izquierda -que sugiere lo 
celestial/ divino- y la mujer mestiza que teje, a la derecha del cuadro -que alude a lo terrenal/mortal.

Desde la sutileza de su dibujo hasta la terrosidad de sus textiles, Martha Cajías explora una diversa gama de soportes, medios, técnicas y tradiciones mitológicas, sirviéndose de sus potenciales intrínsecos para revelar una visión íntima de un mundo que nos habla de cuerpo, memoria, ser y conocimiento, pero también de la relación dinámica entre todos estos elementos que se evidencia en un tiempo/espacio común: el corpus de su obra. Su búsqueda se hace más compleja progresivamente, a partir de una unidad discursiva modular, iterada y evolucionada de forma tal que la propuesta se construye incrementalmente a partir de las nuevas percepciones obtenidas; éstas, a su vez, enriquecen la capacidad de codificación de la artista y, en consecuencia, las posibilidades interpretativas de su obra. 


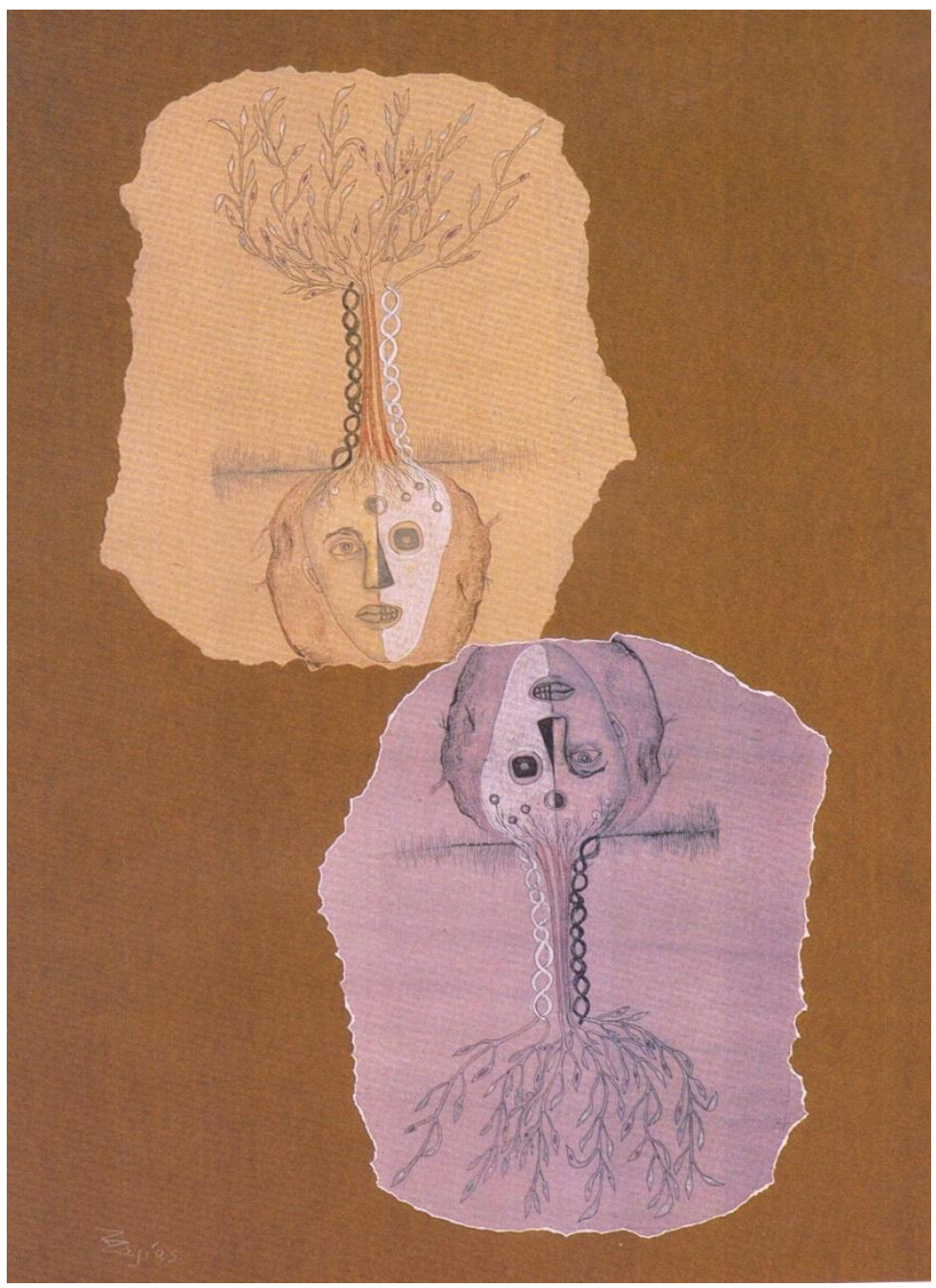

Figura 2. Flor de papa 1 (2003)

Dibujo y técnicas mixtas 


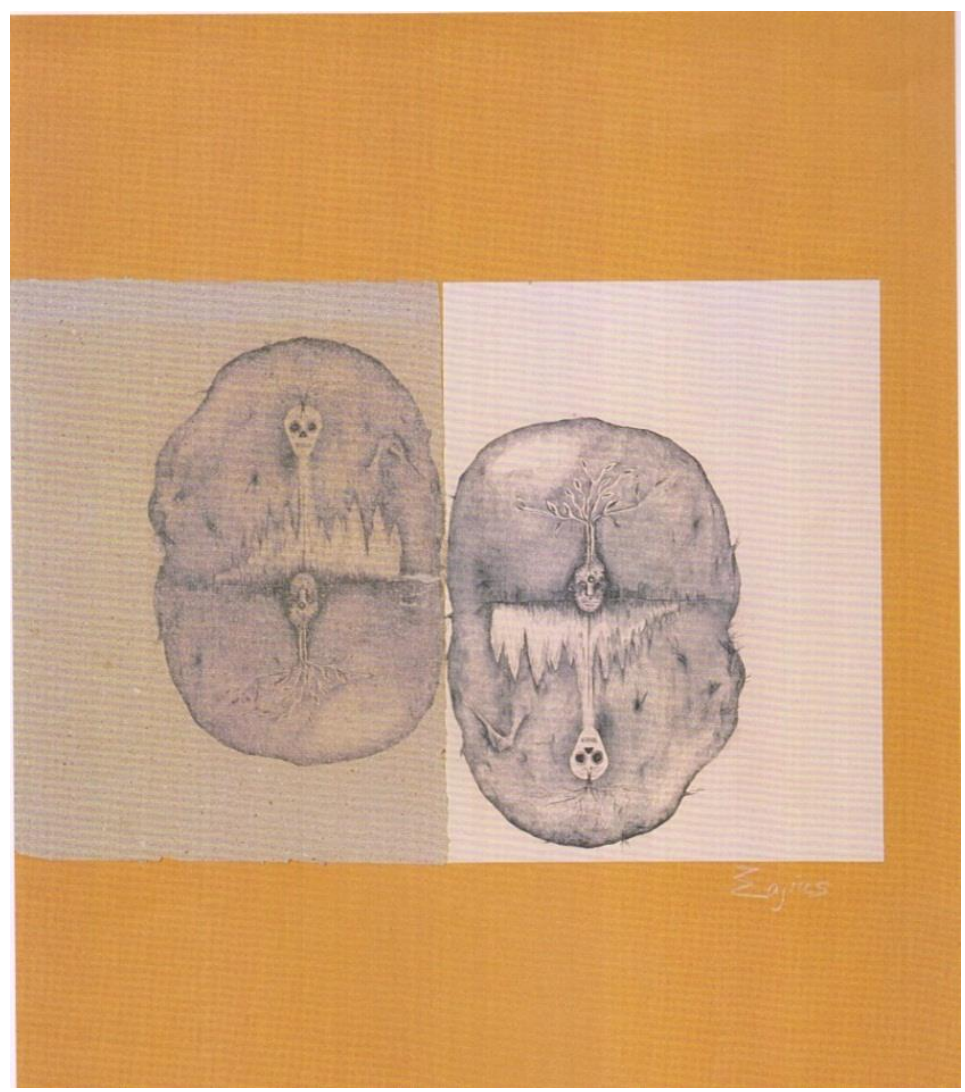

Figura 3. Flor de papa 3 (2003)

Dibujo y técnicas mixtas 


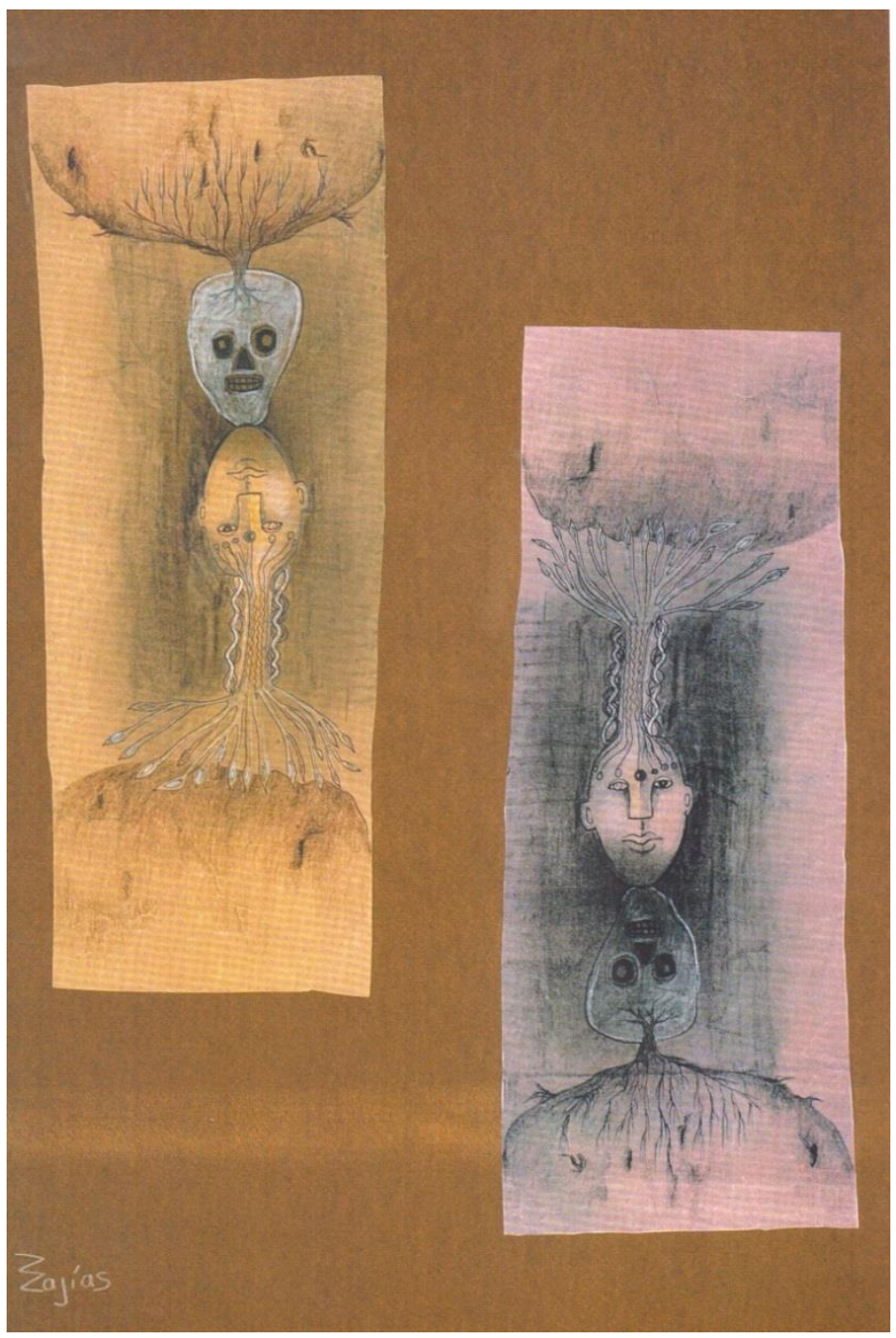

Figura 4. Flor de papa 4 (2003)

Dibujo y técnicas mixtas 


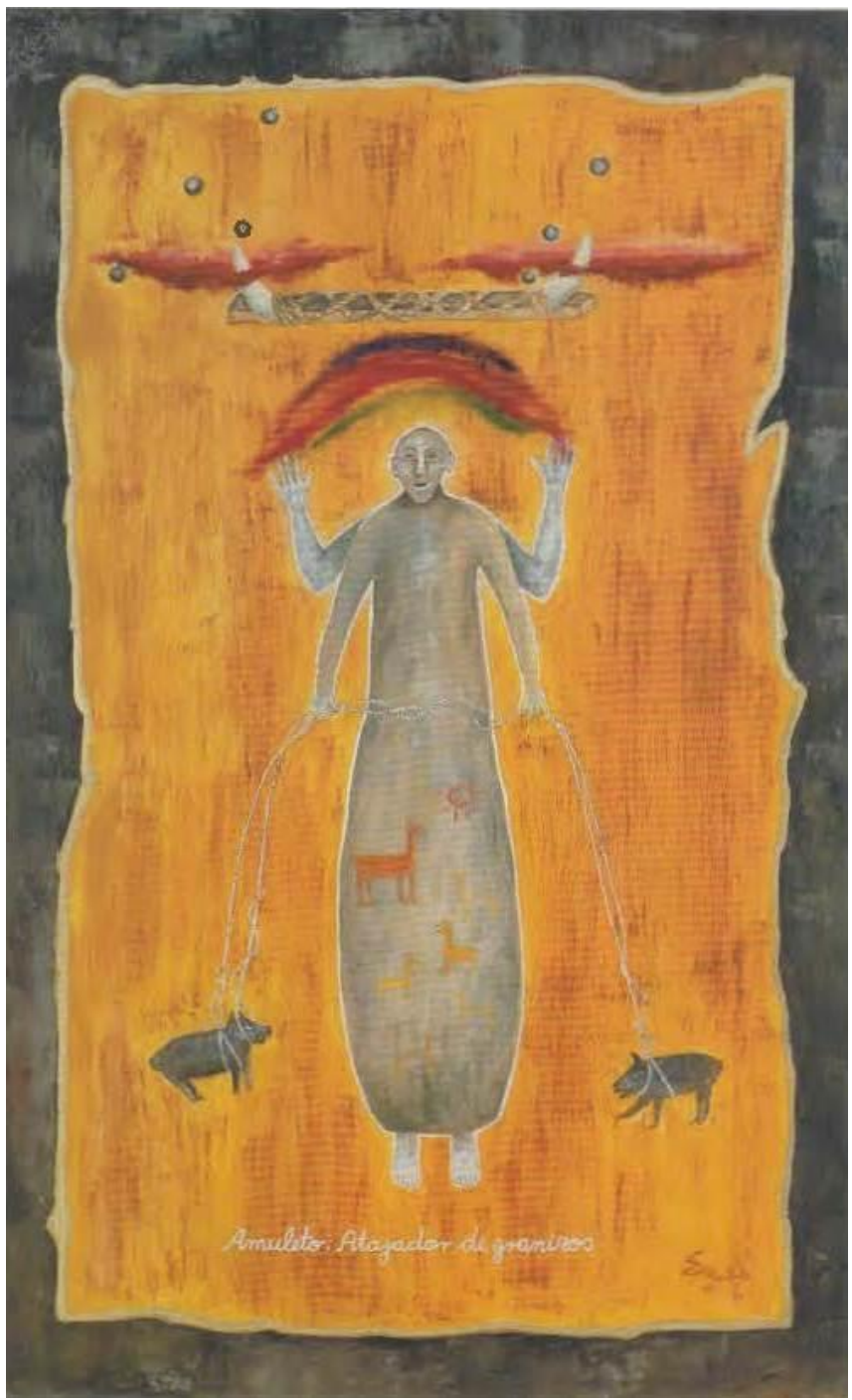

Figura 5. Amuleto: Atajador de granizos (2003)

Óleo sobre lienzo y collage 


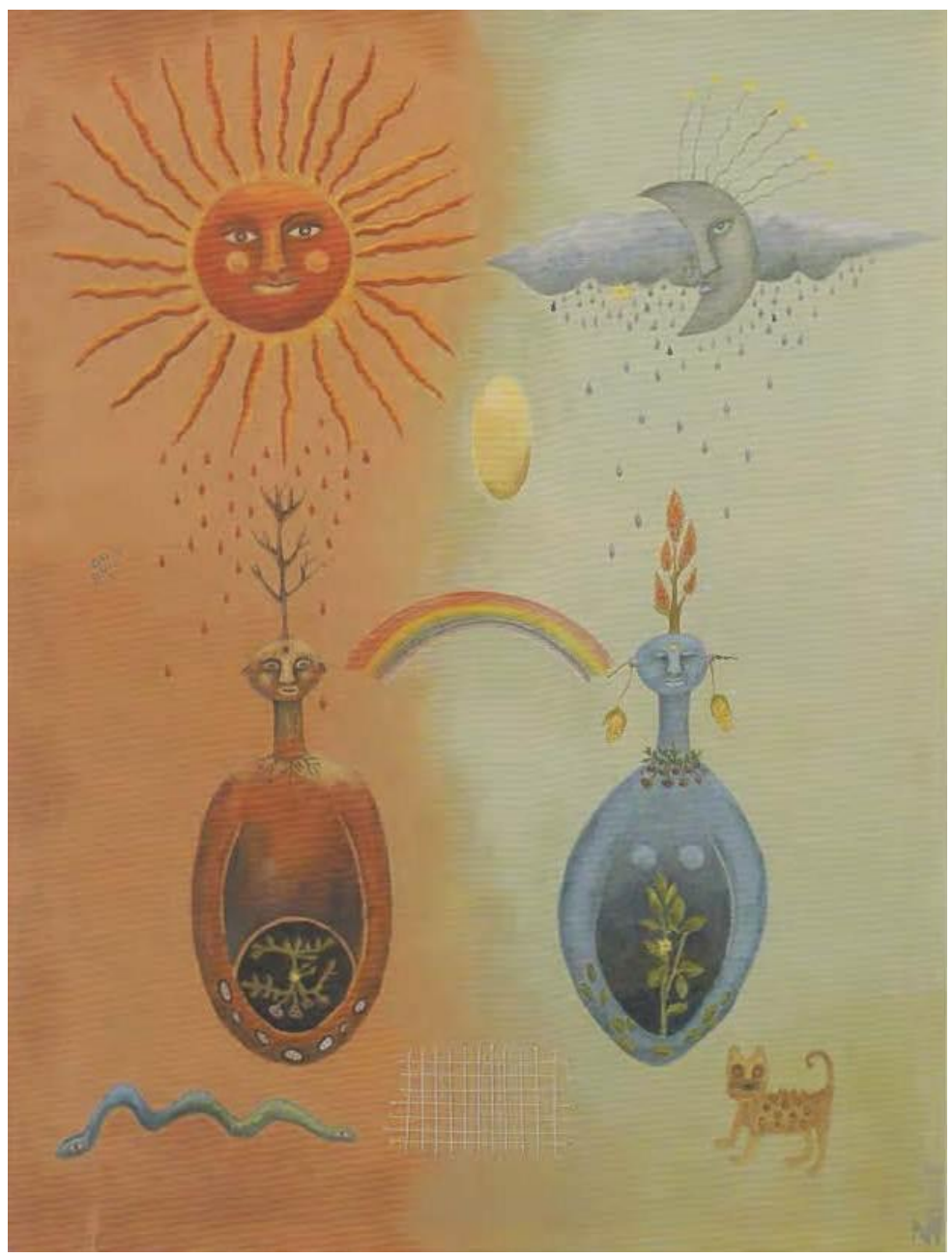

Figura 6. La Seca y la Húmeda (2002)

óleo sobre lienzo y pita entretejida 


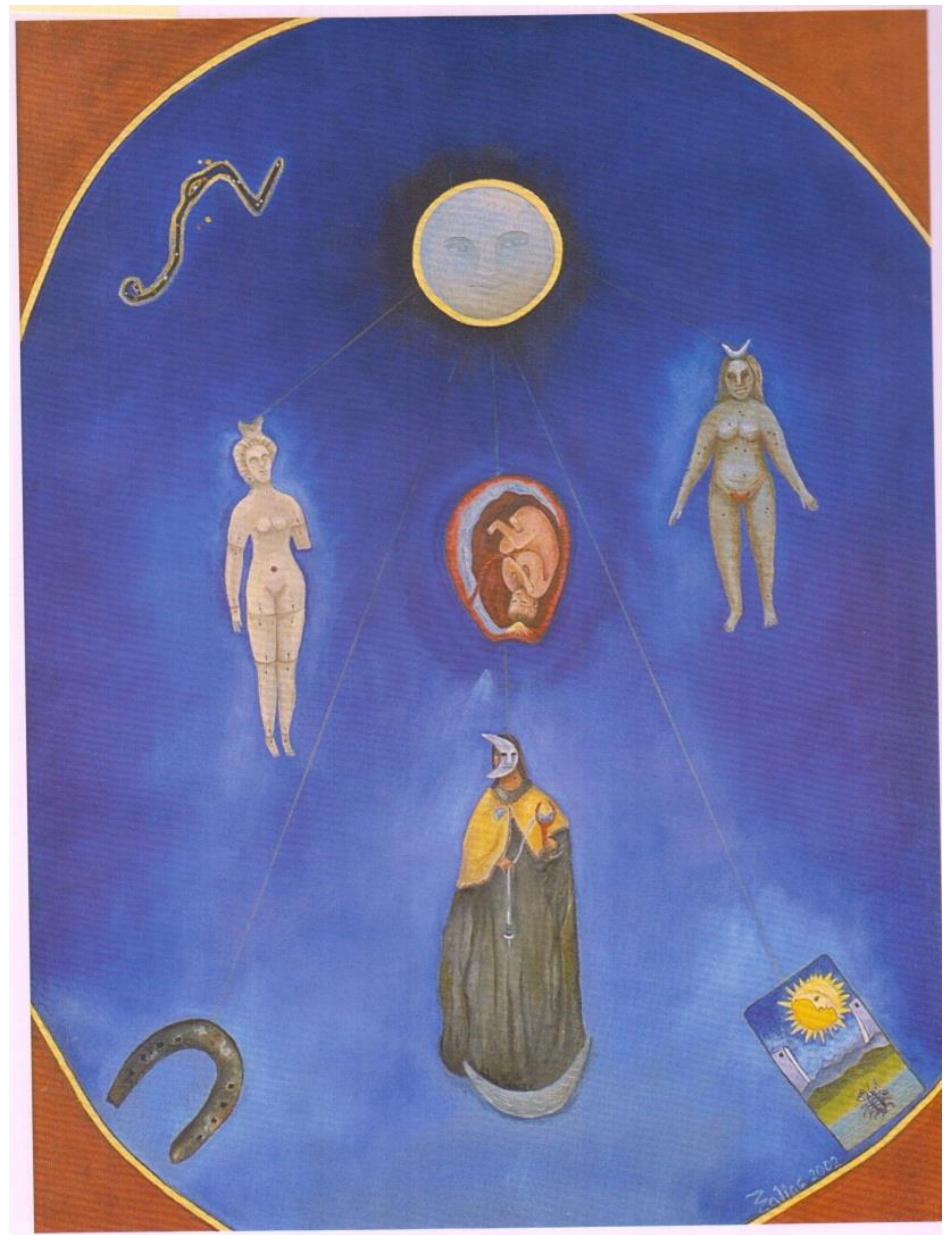

Figura 7. Lunares (2003)

óleo sobre lienzo 


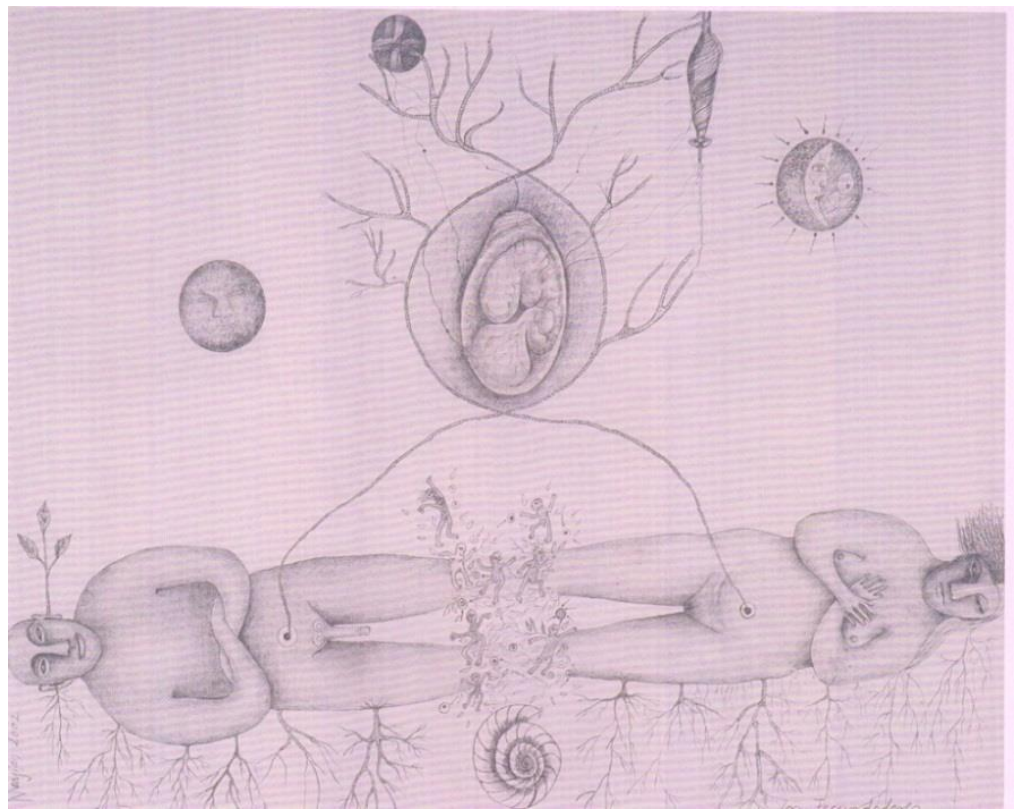

Figura 8. Los Fecundadores (2002)

Dibujo a lápiz 


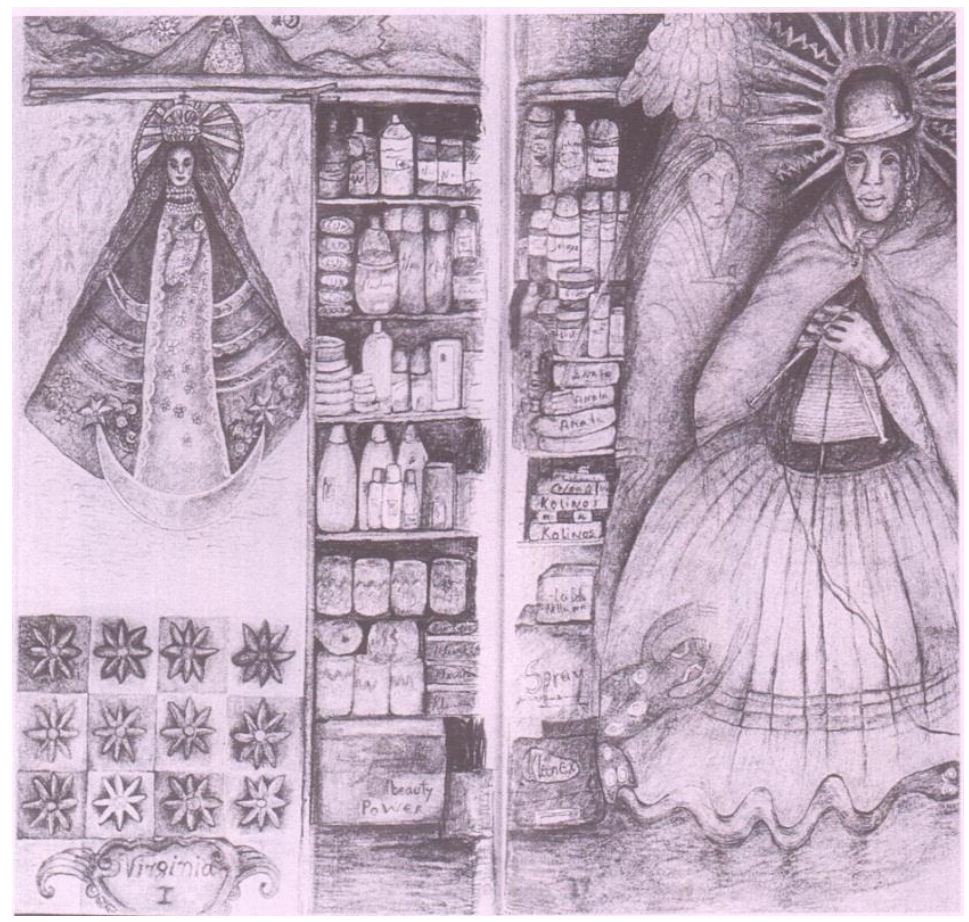

Figura 9. Vírgenes y Virginias (1997)

Dibujo a lápiz y técnicas mixtas

(cc) BY-NC-ND

ULS D-Sorle
This work is licensed under a Creative Commons Attribution-

Noncommercial-No Derivative Works 3.0 United States License.

This journal is published by the University Library System of the University of Pittsburgh as part of its D-Scribe Digital Publishing Program, and is cosponsored by the University of Pittsburgh Press. 